\title{
Synthesis, ADMET and Docking Studies of Novel Pyrazoles Incorporating Coumarin Moiety as Tyrosine Kinase (Src) Inhibitors
}

\author{
Faisal M. Aqlan 1,*(i) \\ 1 University of Jeddah, College of Science, Chemistry Department, 21589 Jeddah, P.O. Box 80327, Saudi Arabia; \\ aqlanfaisal@gmail.com (F.A.); \\ * Correspondence: aqlanfaisal@gmail.com;
}

Scopus Author ID 37014421100

Received: 7.01.2021; Revised: 6.02.2021; Accepted: 9.02.2021; Published: 15.02.2021

\begin{abstract}
Novel pyrazoles incorporating coumarin moiety have been synthesized by the 1,3-dipolar cycloaddition reaction of the nitrilimines that were generated in situ from hydrazonyl halides by the action of triethylamine and the enaminone named E-3-(3-(dimethylamino)acryloyl)-8-methoxy-2Hchromen-2-one (1) in dry benzene for $6 \mathrm{~h}$. These novel compounds' chemical structures were elucidated by physical and spectral techniques, including FTIR, ${ }^{1} \mathrm{H}-\mathrm{NMR},{ }^{13} \mathrm{C}-\mathrm{NMR},{ }^{1} \mathrm{H}-{ }^{13} \mathrm{C}$ HMBC NMR, and mass spectra. These molecules were predicted to show tyrosine kinase inhibition activity, which was further validated by docking studies. These molecules also showed good ADMET properties and passed Lipinski's filters for drug-likeness. These results collectively paved the way for developing pyrazoles incorporating coumarin moiety as possible tyrosine kinase inhibitors.
\end{abstract}

Keywords: 1,3-dipolar cycloaddition; pyrazoles; coumarin; tyrosine kinase; docking.

(C) 2021 by the authors. This article is an open-access article distributed under the terms and conditions of the Creative Commons Attribution (CC BY) license (https://creativecommons.org/licenses/by/4.0/).

\section{Introduction}

Coumarins are an important class of phytochemicals and comprise a benzopyrones family, widely distributed in nature [1]. These oxygen-containing heterocycles, bearing a typical benzopyrone framework, either synthetic or natural, are interested in contemporary drug discovery [2, 3]. Coumarin derivatives are being actively studied for their pharmacological activities and enormous efforts have been put into the design and development of coumarinbased anticoagulants, antioxidant [4], antimicrobial (anti-viral, antifungal, and anti-parasitic) [5, 6], anticancer [7-9], anti-diabetic, analgesic, anti-neurodegenerative, and anti-inflammatory agents [10]. Coumarin-based compounds are also believed to occupy an important place in medicinal chemistry and drug discovery due to the possibility of getting structurally diverse molecules with interesting biological activities from this ring structure [11, 12].

An efficient medicinal chemistry strategy to discover new drug molecules has been the clubbing together of two or more biologically important structural motifs in one molecule. These molecules, often in the form of hybrid molecules, sometimes known as hybrid drugs, are more efficient with better efficacy than the individual molecules [13, 14]. Many synthetic intermediates are quite useful to synthesize such hybrid molecules, among which enaminones are considered important synthetic intermediates for the synthesis of various heterocyclic compounds $[15,16]$. The importance of the enaminone such as E-3-(3(dimethylamino)acryloyl)-8-methoxy-2H-chromen-2-one (1) due to its unique structure (Fig. 
1), which facilitates the 1,3-dipolar cycloaddition with nitrilimines (liberated, in situ, by the action of the base on the corresponding hydrazonyl halides), to synthesize the pyrazoles. In turn, pyrazoles are considered to be pharmacologically important and active scaffolds that possess almost all types of pharmacological activities [17-19]. In continuation of our research work in the area of synthesis of heterocyclic compounds for different applications [20-22], we present this work that aims to synthesize novel pyrazole derivatives containing coumarin moiety utilizing efficient synthetic strategies. In silico studies of these molecules were also conducted to unravel their potential as biologically important scaffolds.

Electron Rich Carbon

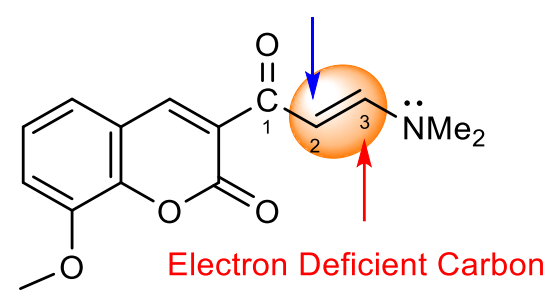

Figure 1. Structure of enaminone 1.

\section{Materials and Methods}

\subsection{Chemistry.}

All organic solvents were purchased from commercial sources and used as received unless otherwise stated. All other chemicals were purchased from Merck, Aldrich, or Acros and used without further purification. Thin-layer chromatography (TLC) was performed on precoated Merck 60 GF254 silica gel plates with a fluorescent indicator and detection by means of UV light at 254 and $360 \mathrm{~nm}$. The melting points were measured on a Stuart melting point apparatus and are uncorrected. IR spectra were recorded on a Smart iTR, an ultra-highperformance, versatile Attenuated Total Reflectance (ATR) sampling accessory on the Nicolet iS10 FT-IR spectrometer. The NMR spectra were recorded on a Bruker Avance III 400 (9.4 T, 400.13MHz for ${ }^{1} \mathrm{H}, 100.62 \mathrm{MHz}$ for ${ }^{13} \mathrm{C}$ and $376.25 \mathrm{MHz}$ for ${ }^{19} \mathrm{~F}$ ) spectrometer with a $5-\mathrm{mm}$ BBFO probe, at $298 \mathrm{~K}$. Chemical shifts ( $\delta$ in $\mathrm{ppm})$ are given relative to internal solvent, DMSO-d6 2.50 for ${ }^{1} \mathrm{H}$ and 39.50 for ${ }^{13} \mathrm{C}$ was used as an external standard. $\left({ }^{1} \mathrm{H}^{-13} \mathrm{C}\right)$ gs-HMBC was acquired and processed using standard Bruker NMR software (Topspin 3.2). Mass spectra were recorded on a Thermo ISQ Single Quadrupole GC-MS. Elemental analyses were carried out on a EuroVector instrument C, H, N, S analyzer EA3000 Series.

E-3-(3-(dimethylamino)acryloyl)-8-methoxy-2H-chromen-2-one (1) [23] and $N$-Aryl2-oxopropanehydrazonoyl chloride 2a-c [24] were synthesized according to literature procedures.

\subsubsection{General procedure for 1,3-dipolar cycloaddition reaction.}

To a hot solution of enaminone $1(10 \mathrm{mmol})$ and the appropriate hydrazonyl halide $2 \mathrm{a}$ $\mathrm{c}(10 \mathrm{mmol})$ in benzene $(25 \mathrm{~mL})$, triethylamine $(10 \mathrm{mmol})$ was added. The reaction mixture was refluxed for $7 \mathrm{~h}$. (until no starting materials showed by in TLC). The solvent was evaporated under reduced pressure. The solid product was crystallized from ethanol to afford the corresponding pyrazole derivatives $5 \mathrm{a}-\mathrm{c}$. 
2.1.2. 3-(3-acetyl-1-phenyl-1H-pyrazole-4-carbonyl)-8-methoxy-2H-chromen-2-one (5a).

m.p. $=165{ }^{\circ} \mathrm{C} ;$ IR $(\mathrm{KBr}) \quad v / \mathrm{cm}^{-1}: 1644,1718,1738 \quad(3 \mathrm{C}=\mathrm{O}), 1593 \quad(\mathrm{C}=\mathrm{N})$; ${ }^{1} \mathrm{HNMR}\left(\mathrm{DMSO}-d_{6}\right): \delta \quad 2.56$ (s, 3H, COMe), 3.92 (s, 3H, OMe), 7.34-7.60 (m, 6H, Ar H), $8.02(\mathrm{~d}, 2 \mathrm{H}, \mathrm{J}=8 \mathrm{~Hz}, \mathrm{ArH}), 8.57(\mathrm{~s}, 1 \mathrm{H}$, coumarin $\mathrm{H} 4), 9.22(\mathrm{~s}, 1 \mathrm{H}$, pyrazole $\mathrm{H}) ;{ }^{13} \mathrm{C}$ NMR(DMSO-d6): $\delta$ 27.7, 56.6, 119.4, 119.8, 119.9, 121.8, 124.1, 124.9, 125.4, 130.3, 134.1, 146.6,146.8,158.9, 185.9,193.4; MS (m/z): $388\left(\mathrm{M}^{+}\right)$; $\mathrm{C}_{22} \mathrm{H}_{16} \mathrm{~N}_{2} \mathrm{O}_{5}$ :Anal. Calcd: C, 68.04; H, 4.15; N, 7.21. Found: C, 68.27; H, 4.05; N, 7.08.

2.1.3. 3-(3-acetyl-1-(4-tolyl)-1H-pyrazole-4-carbonyl)-8-methoxy-2H-chromen-2-one (5b).

m.p. $=200^{\circ} \mathrm{C} ; \quad \mathrm{IR}(\mathrm{KBr}) \quad \mathrm{c} / \mathrm{cm}^{-1}: 1648, \quad 1718, \quad 1736 \quad(3 \mathrm{C}=\mathrm{O}), 1601 \quad(\mathrm{C}=\mathrm{N})$; ${ }^{1} \mathrm{HNMR}\left(\mathrm{DMSO}-d_{6}\right): \delta \quad 2.39$ (s, 3H, Me), 2.87 (s, 3H, COMe), 3.92 (s, 3H, OMe), 7.30-7.48 (m, 5H, Ar H), 7.99 (d, 2H, J = 8.4 Hz, ArH), 8.55 (s, 1H, coumarin H4), 9.16 (s, 1H, pyrazole $\mathrm{H}) ;{ }^{13} \mathrm{C}$ NMR(DMSO-d6): $\delta 21.0,27.7,56.5,116.5,119.4,119.8,121.2,121.7,124.0,124.9$, 125.4, 127.3, 130.6, 133.9, 136.6, 146.1, 146.6, 158.9, 184.9,194.5; MS (m/z): $402\left(\mathrm{M}^{+}\right)$; $\mathrm{C}_{23} \mathrm{H}_{18} \mathrm{~N}_{2} \mathrm{O} 5$ :Anal. Calcd: C, 68.65; H, 4.51; N, 6.96. Found: C, 68.94; H, 4.43; N, 6.75.

2.1.4. 3-(3-acetyl-1-(4-trifluromethylphenyl)-1H-pyrazole-4-carbonyl)-8-methoxy-2Hchromen-2-one (5c).

m.p. $=224{ }^{\circ} \mathrm{C} ; \quad$ IR $(\mathrm{KBr}) \quad v / \mathrm{cm}^{-1}: 1645,1718,1735 \quad(3 \mathrm{C}=\mathrm{O}), 1601 \quad(\mathrm{C}=\mathrm{N})$; ${ }^{1} \mathrm{HNMR}\left(\mathrm{DMSO}-d_{6}\right): \delta \quad 2.58$ (s, 3H, COMe), 3.83 (s, 3H, OMe), 7.32-7.49 (m, 7H, Ar H), 8.60 (s, $1 \mathrm{H}$, coumarin $\mathrm{H} 4), 9.22$ (s, $1 \mathrm{H}$, pyrazole $\mathrm{H}$ ); ${ }^{13} \mathrm{C}$ NMR(DMSO-d6): $\delta 30.5,56.7,116.9$, 119.1, 121.3, 121.9, 122.1, 124.9, 125.3, 126.2, 127.4, 130.1, 132.8, 144.4, 146.7, 147.7, 158.6, 183.6,195.6; MS (m/z): $456\left(\mathrm{M}^{+}\right)$; $\mathrm{C}_{23} \mathrm{H}_{15} \mathrm{~F}_{3} \mathrm{~N}_{2} \mathrm{O}$ 5:Anal. Calcd: C, 60.53; H, 3.31; N, 6.14. Found: C, 60.76; H, 3.22; N, 6.00 .

\subsection{In silico Studies}

\subsubsection{Target prediction.}

To estimate the most probable macromolecular target for the synthesized compounds (5a-5c) they were screened by an online web tool: Swiss TargetPrediction [25]. SwissTargetPrediction is a web-based tool to perform ligand-based target prediction for any small bioactive molecule. Prediction of the target is based on the similarity principle through reverse screening.

\subsubsection{ADMET and pharmacokinetic studies.}

ADMET and pharmacokinetic properties were checked using pkCSM (A Cambridge online source, link: http://bleoberis. bioc.cam.ac.uk/pkcsm/prediction) and validated using MedChemDesigner ${ }^{\mathrm{TM}}$ software version 3.0 [26]. The structures of the compounds $5 \mathrm{a}-5 \mathrm{c}$ and their physicochemical properties were drawn and calculated using MarvinSketch.

\subsubsection{Docking studies.}

The molecules (5a-5c) as ligands were drawn in ChemDraw Ultra 12.0 (Chem Office package) assigned with proper 2D orientation and analyzed for connection error in bond order. OSIRIS, an ADMET-based Java library layer that provides reusable cheminformatics 
functionality, an entirely in-house developed drug discovery informatics system, was used to predict the total drug score. Dundee PRODRG2 server was used to minimize the energy of the molecules [27, 28]. The energy minimized compounds were then read as input for AutoDock4.2 in order to carry out the docking simulation. Auto Dock used the local search to search for small molecules' optimum binding site to the protein. The active site was defined by a grid box of $85 \times 80 \times 90$ points and spacing of $0.375 \AA$ with the ligand-binding site as the center. The final structure was then saved in pdbqt format. During the docking process, a maximum of 10 conformers was considered for each compound. AutoDock 4.2 and AutoDockvina were compiled and run under Windows 7 operating system [29]. The images were visualized using PyMoL.

\section{Results and Discussion}

\subsection{Synthesis.}

The enaminone 1 reacted with $\alpha$-ketohydrazonylhalide $2 \mathrm{a}-\mathrm{c}$ in a regioselective manner to afford only one isolable product as examined by TLC. The structures of the products formed may be $5 \mathrm{a}-5$ cor other regioisomers $7 \mathrm{a}-7 \mathrm{c}($ Scheme 1$)$.

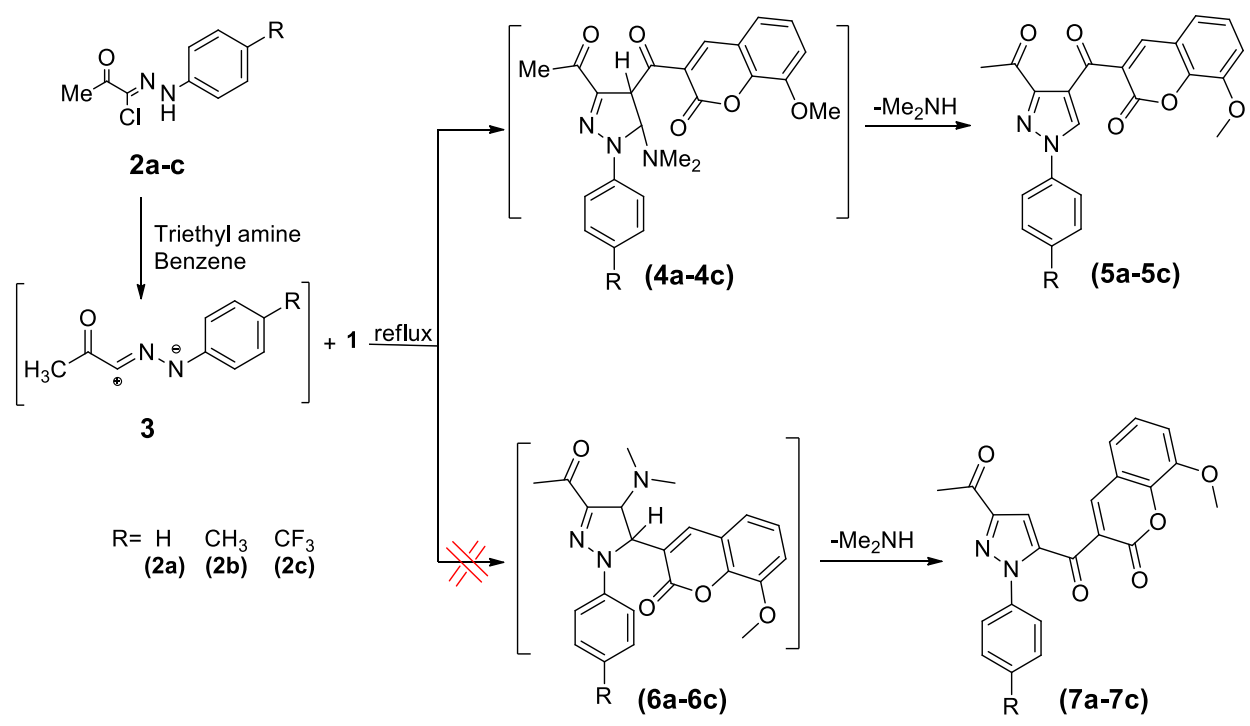

Scheme 1. Regioselective reaction between enaminone and hydrazonyl halides.

As mentioned before, the differentiation between the two possible regioisomers can be easily done via the long-range $\mathrm{C}-\mathrm{H}$ connectivitiesutilizing ${ }^{1} \mathrm{H}-{ }^{13} \mathrm{C} \mathrm{HMBC}$ depending on the correlation between the pyrazole proton with the carbons of the two carbonyl groups $[24,30]$. Here in our case, we first can assign the three carbons of carbonyl groups from the ${ }^{1} \mathrm{H}-{ }^{13} \mathrm{C}$ HMBC full spectrum of the isolated product $5 \mathrm{a}$ or $7 \mathrm{a}$. In which a signal was observed at $\delta$ $158.9 \mathrm{ppm}$ corresponding to the carbonyl carbon of coumarin; it exhibited a correlation peak with the signal at $\delta 8.57 \mathrm{ppm}$ assigned to the coumarin H-4. A signal at $\delta 193.4 \mathrm{ppm}$ corresponds to the carbonyl carbon due to its correlation peak with the signal at $\delta 2.56 \mathrm{ppm}$ assigned to the acetyl group's methyl protons. On the other hand, the signal at $\delta 185.9 \mathrm{ppm}$ is attributed to the other carbonyl group, owing to its correlation peak with the signal at $\delta 9.22$ ppm, easily assigned to the pyrazole proton (Figure2). These observations indicate that only one carbonyl functional group correlates to the pyrazole proton $\left({ }^{3} J_{\mathrm{H}-\mathrm{C}}\right)$, following the structure $7 \mathrm{a}$, in addition to the other observed correlations of the pyrazole protons with $\mathrm{C}-4$ pyrazole 
$\left({ }^{2} J_{\mathrm{H}-\mathrm{C}}\right), \mathrm{C}-3$ pyrazole $\left({ }^{3} J_{\mathrm{H}-\mathrm{C}}\right)$, and the deshielded quaternary carbon of the phenyl group $\left({ }^{3} J_{\mathrm{H}-\mathrm{C}}\right)$ (Fig. 1 and see supporting information).

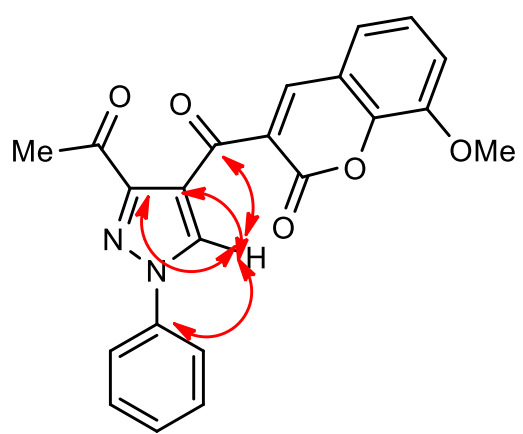

(5a)

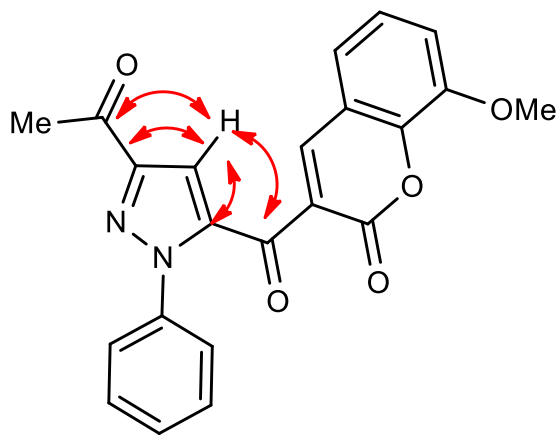

(7a)

Figure 2. Diagnostic correlations in the ${ }^{1} \mathrm{H}_{-}{ }^{13} \mathrm{C}$ HMBC (red arrows) for two regioisomers5a and 7a.

Therefore, these results confirm the existence of regioisomer $5 \mathrm{a}$ and rule out the alternative structure $7 \mathrm{a}$. The formation of novel pyrazole derivative $5 \mathrm{a}$ was assumed to be formed via initial 1,3-dipolar cycloaddition of the nitrilimine 3 ( generated in situ form of hydrazonyl halid 2 a upon treatment with triethylamine) to the activated double bond in the enaminone 1 to afford the dihydropyrazole transition state $4 \mathrm{a}$, followed by elimination of dimethylamine, yielding the pyrazole derivative 5a (Scheme 1). The other derivatives follow the same reaction route.

\subsection{ADMET and pharmacokinetic studies.}

To make sure that the synthesized molecules show the potential of a drug, their ADMET and pharmacokinetic properties were checked using pkCSM (A Cambridge online source, link: http://bleoberis. bioc.cam.ac.uk/pkcsm/prediction) and validated using MedChemDesigner ${ }^{\mathrm{TM}}$ software version 3.0 [26] which predicts the values with great precision. The predicted values showed that the molecules have a great solubility potential, both in water (5a) -3.969 (log mol/L), (5b) -4.021 (5c)-4.086 and $\mathrm{CaCO}_{2}$ permeability (5a) 1.557, (5b) 1.41, (5c) 0.856 (log Papp in $10 \mathrm{~cm} / \mathrm{s}$ ). Intestinal absorption (human) (5a) 100(5b) 100, (5c) 97.06(\% Absorbed) and skin permeability (5a, 5b \& 5c) $\quad-2.735$, (log Kp). BBB permeability (5a) -0.966,(5b) -0.98 , (5c)-1.404 ( $\log$ BB) and CNS permeability (5a) -2.433 , (5b) $-2.359,(5 c)-2.275(\log$ PS). The molecule's ability to inhibit CYP1A2, CYP3A4, CYP2C9, and CYP2C19 shows that the molecule will not allow the metabolism of xenobiotics in the body. The value of clearance, which is the pharmacokinetic parameter that represents the rate of drug elimination divided by its plasma concentration, is quite favorable for the molecules (5a) $0.813(5 b) 0.815$, and (5c) $0.334 \log \mathrm{ml} / \mathrm{min} / \mathrm{kg}$ and implies that the molecule would not accumulate in the body and hence is nontoxic. Oral Rat Acute Toxicity (LD50) was (5a) 2.702(5b) 2.715, (5c) $2.787 \mathrm{~mol} / \mathrm{kg}$ and Oral Rat Chronic Toxicity (LOAEL) was (5a) 1.092 (5b) 1.166, (5c) 0.589 (log $\mathrm{mg} / \mathrm{kg} \_$bw/day). These results depict that the compound has good ADMET properties, which are a requisite for a molecule to show drug-like properties.

The predicted pharmacokinetic parameters and other physicochemical properties, often known as Lipinski's filters, are important for both in silico and in vitro evaluation of drug-like properties [31-33]. A molecule that lacks good pharmacokinetic parameters and does not obey Lipinski's filters fails in the later stages of drug development. From the predicted pharmacokinetic parameters and after applying Lipinski's filters (shown in Table 1) it appears 
that the molecules show good drug-likeness properties and could be a good drug candidate for further studies.

Table 1. ADMET and Lipinski's filters for drug-likeness.

\begin{tabular}{c|c|c|c|c|c|c|c} 
Compound & M.Wt & $\mathbf{C l o g P}^{*}$ & $\mathbf{L o g D}^{\#}$ & ${ }^{\mathbf{a}} \mathbf{H B A}$ & $\mathbf{H B D}$ & $\mathbf{P S A}$ & $\mathbf{R o 5}(\mathbf{Y} / \mathbf{N})$ \\
\hline $\mathbf{5 a}$ & 388.37 & 2.51 & 3.00 & 7 & 0 & 87.49 & $\mathrm{Y}$ \\
\hline $\mathbf{5 b}$ & 402.12 & 2.99 & 3.51 & 7 & 0 & 85.27 & $\mathrm{Y}$ \\
\hline $\mathbf{5 c}$ & 456.37 & 3.43 & 3.87 & 7 & 0 & 85.27 & $\mathrm{Y}$ \\
\hline & & & & & & &
\end{tabular}

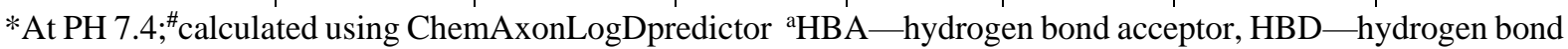
donor, PSA — polar surface area obtained by Marvin Sketch 5.1. "Values adopted from referred sources. Ro5 $(\mathrm{Y} / \mathrm{N})$ : Rule of five followed or not; Y: Yes; N: No

\subsection{Molecular docking studies.}

A molecular docking study of the compounds (5a-5c) was performed to validate the predicted target. 2D structures of the molecules were converted to energy minimized 3D structures and were further used for docking. The molecules were docked into the active sites of tyrosine kinase (PDB ID: 2SRC). It was found that the molecules interact with different residues inside the active site of the enzyme. The binding free energy for these molecules was found to be in the range of -15.55 to $-17.92 \mathrm{kcal} / \mathrm{mol}$, which shows that the inhibitor binds well inside the active site pocket (see Figure 3 ). The molecule also showed hydrogen bonding, hydrophobic and other interactions with the target, explaining its good antibacterial activity.

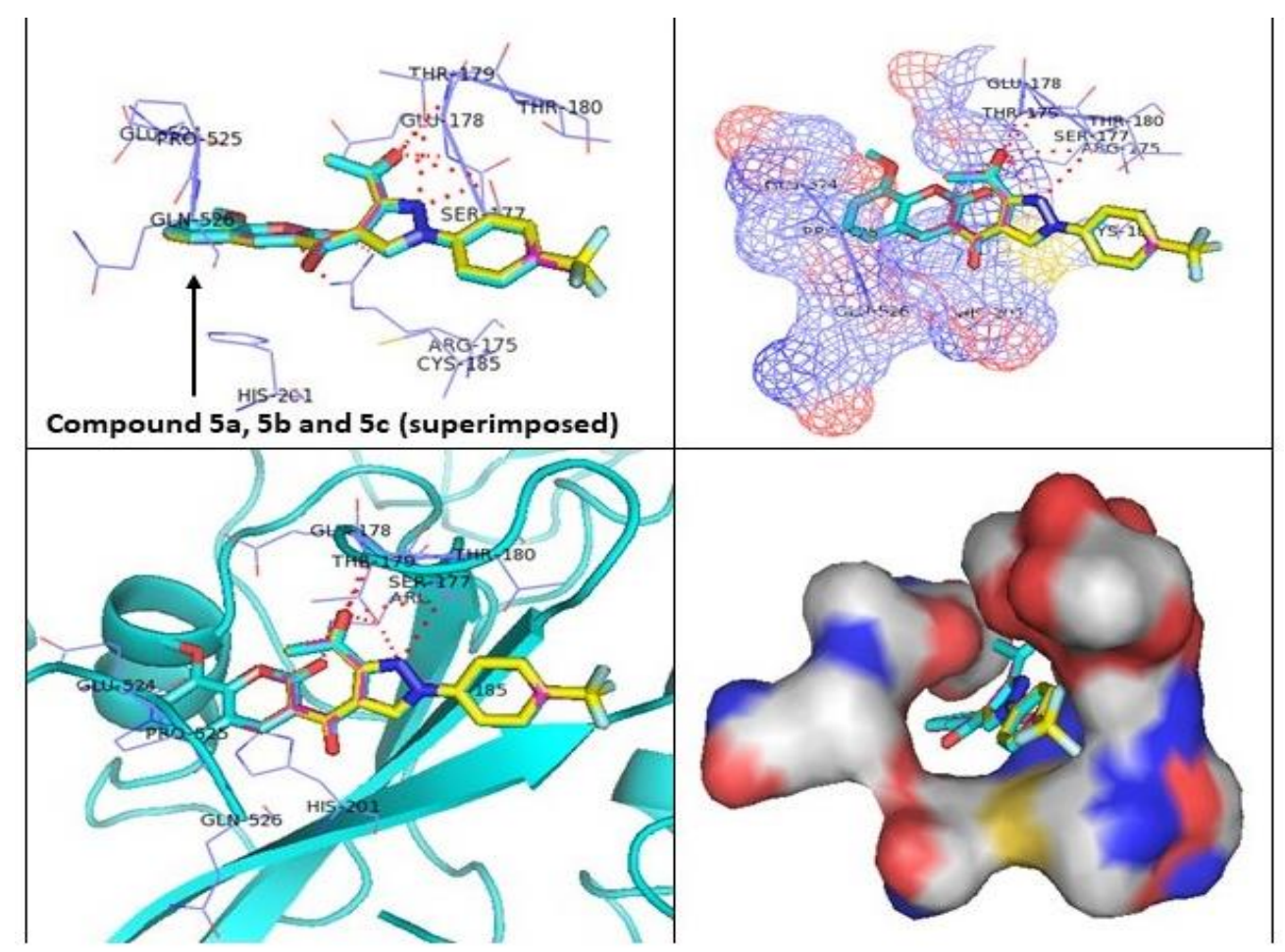

Figure 3. Docking poses of the compounds (5a-5c) inside the active site pocket of tyrosine kinase (2SRC). All the molecules show similar binding interactions, and their structures are superimposed in the images.

The acetyl group's oxygen atom attached to the pyrazole ring showed hydrogen bonding interaction with SER177, GLU178, and THR179 amino acid residues of the target enzyme. The nitrogen atom of the pyrazole ring showed hydrogen bonding interaction with SER177 and THR179. The coumarin ring formed hydrogen bonds with ARG175 amino acid residue of the target enzyme. The other active pocket residues THR180, CYS185, HIS201, GLU524, 
PRO525, and GLN526 of the enzyme were involved in van der Waal's interactions, hydrophobic and $\pi-\pi$ staking interactions.

Tyrosine kinase inhibitors (TKI) are effective in the targeted treatment of different types of malignancies. Tyrosine kinase (sar) enzymes catalyze the transfer of $\gamma$ - phosphate group from adenosine triphosphate to the target proteins, which play an important role in diverse normal cellular regulatory processes [34]. Several tyrosine kinase inhibitors as drug molecules are already used in the clinic, such as Imatinib, the first clinically approved TKI. Imatinib was later followed by drugs such as gefitinib, erlotinib, sorafenib, sunitinib, and dasatinib. The 2-amino benzoxazole and benzimidazole derivatives and pyrazolyl-benzoxazole derivatives have been proved to be active tyrosine kinase inhibitors due to strong binding affinity enzyme [35, 36, 37]. Our results also corroborate these findings. Therefore, these hybrid molecules containing a coumarin ring and pyrazole moiety could be good scaffolds for designing new tyrosine kinase inhibitors. These molecules also showed good ADMET properties and passed Lipinski's filters for drug-likeness. These results collectively paved the way for the development of pyrazoles incorporating coumarin moiety as tyrosine kinase inhibitors.

\section{Conclusions}

1,3-dipolar cycloaddition reaction of the nitrilimines that were generated in situ from hydrazonyl halides by the action of triethylamine and the enaminone named E-3-(3(dimethylamino)acryloyl)-8-methoxy-2H-chromen-2-one (1) in dry benzene for $6 \mathrm{~h}$ gave rise to new pyrazoles incorporating coumarin moiety in their skeleton. These compounds' structures were elucidated by different physical and spectral techniques, including FTIR, ${ }^{1} \mathrm{H}-\mathrm{NMR},{ }^{13} \mathrm{C}$ $\mathrm{NMR},{ }^{1} \mathrm{H}-{ }^{13} \mathrm{C}$ HMBC NMR, and mass spectra. These molecules were predicted to target tyrosine kinase, which was further validated by docking studies. These molecules fit well in the active site pocket of the target enzyme and displayed good drug-likeness properties. Overall, these molecules possessed good ADMET properties, passed Lipinski's filters for druglikeness, and showed a good binding affinity with the target. These results are quite encouraging owing to the development of new tyrosine kinase inhibitors as potential drug molecules.

\section{Funding}

This research received no external funding.

\section{Acknowledgments}

The author is thankful to the Chemistry Department, the University of Jeddah, for providing research facilities.

\section{Conflicts of Interest}

The authors declare no conflict of interest.

\section{References}

1. Stefanachi, A.; Leonetti, F.; Pisani, L.; Catto, M.; Carotti, A. Coumarin: A Natural, Privileged and Versatile Scaffold for Bioactive Compounds. Molecules 2018, 23, https://doi.org/10.3390/molecules23020250. 
2. Golonko, A.; Lewandowska, H.; Świsłocka, R.; Jasińska, U.T.; Priebe, W.; Lewandowski, W. Curcumin as tyrosine kinase inhibitor in cancer treatment. European Journal of Medicinal Chemistry 2019, 181, https://doi.org/10.1016/j.ejmech.2019.07.015.

3. Zhang, L.; Xu, Z. Coumarin-containing hybrids and their anticancer activities. European Journal of Medicinal Chemistry 2019, 181, https://doi.org/10.1016/j.ejmech.2019.111587.

4. Yasameen, Al-M.; Ahmed, Al-A.; Abdul, A.-K.; Abu, B.-M. Antioxidant Activity of Coumarins. Sys Rev Pharm. 2017, 8, DOI : 10.5530/srp.2017.1.6

5. Regal, M.K.A.; Shaban, S.S.; El-Metwally, S.A. Synthesis and antimicrobial activity of some new coumarin and dicoumarol derivatives. Journal of Heterocyclic Chemistry 2020, 57, 1368-1378, https://doi.org/10.1002/jhet.3873.

6. Carneiro, A.; Matos, M.J.; Uriarte, E.; Santana, L. Trending Topics on Coumarin and Its Derivatives in 2020. Molecules 2021, 26, https://doi.org/10.3390/molecules26020501.

7. Al-Warhi, T.; Ahmed, S.; Eslam, B.; Wagdy, M. Recent advancements of cou marin-based anticancer agents: An up-to-date review. Bioorg. Chem 2020, 103, https://doi.org/10.1016/j.bioorg.2020.104163.

8. Vazquez-Rodriguez, S.; Vilar, S.; Kachler, S.; Klotz, K.-N.; Uriarte, E.; Borges, F.; Matos, M.J. Adenosine Receptor Ligands: Coumarin-Chalcone Hybrids as Modulating Agents on the Activity of hARs. Molecules 2020, 25 https://doi.org/10.3390/molecules25184306.

9. Wu, Y.; Xu, J.; Liu, Y.; Zeng, Y.; Wu, G. A Review on Anti-Tumor Mechanisms of Coumarins. Frontiers in Oncology 2020, 10, https://doi.org/10.3389/fonc.2020.592853.

10. Alshibl, H.M.; Al-Abdullah, E.S.; Haiba, M.E.; Alkahtani, H.M.; Awad, G.E.A.; Mahmoud, A.H.; Ibrahim, B.M.M.; Bari, A.; Villinger, A. Synthesis and Evaluation of New Coumarin Derivatives as Antioxidant, Antimicrobial, and Anti-Inflammatory Agents. Molecules 2020, https://doi.org/10.3390/molecules25143251.

11. Annunziata, F.; Pinna, C.; Dallavalle, S.; Tamborini, L.; Pinto, A. An Overview of Coumarin as a Versatile and Readily Accessible Scaffold with Broad-Ranging Biological Activities. International Journal of Molecular Sciences 2020, 21, https://doi.org/10.3390/ijms21134618.

12. O’Kennedy, R.; Thornes, R.D. Coumarins. Biology, Applications and Mode of Action. New York: John Wiley and Sons; 1997.

13. Haythem, A.S.; Mohammad, S.M. Hybrid Drugs as Potential Combatants Against Drug-Resistant Microbes: A Review. Current Topics in Medicinal Chemistry 2017, 17, 895-906, https://doi.org/10.2174/1568026616666160927155251.

14. Shepeta, Y.; Lozynskyi, A.; Sulyma, M.; Nektegayev, I.; Grellier, P.; Lesyk, R. Synthesis and biological activity evaluation of new thiazolidinone-diclofenac hybrid molecules. Phosphorus, Sulfur, and Silicon and the Related Elements 2020, 195, 836-841, https://doi.org/10.1080/10426507.2020.1759060.

15. Stanovnik, B. Enaminone, Enaminoesters, and Related Compounds in the Metal-Free Synthesis of Pyridines and Fused Pyridines. European Journal of Organic Chemistry 2019, 2019, 5120-5132, https://doi.org/10.1002/ejoc.201900797.

16. Huang, J.; Yu, F. Recent Advances in Organic Synthesis Based on N,N-Dimethyl Enaminones. Synthesis 2021, 53, 587-610, https://doi.org/10.1055/s-0040-1707328.

17. Karrouchi, K.; Radi, S.; Ramli, Y.; Taoufik, J.; Mabkhot, Y.N.; Al-aizari, F.A.; Ansar, M.h. Synthesis and Pharmacological Activities of Pyrazole Derivatives: A Review. Molecules 2018, 23, https://doi.org/10.3390/molecules23010134.

18. Bennani, F.E.; Doudach, L.; Cherrah, Y.; Ramli, Y.; Karrouchi, K.; Ansar, M.h.; Faouzi, M.E.A. Overview of recent developments of pyrazole derivatives as an anticancer agent in different cell line. Bioorganic Chemistry 2020, 97, https://doi.org/10.1016/j.bioorg.2019.103470.

19. Assali, M.; Abualhasan, M.; Sawaftah, H.; Hawash, M.; Mousa, A. Synthesis, Biological Activity, and Molecular Modeling Studies of Pyrazole and Triazole Derivatives as Selective COX-2 Inhibitors. Journal of Chemistry 2020, 2020, https://doi.org/10.1155/2020/6393428.

20. Wani, M.Y.; Ahmad, A.; Aqlan, F.M.; Al-Bogami, A.S. Azole Based Acetohydrazide Derivatives of Cinnamaldehyde Target and Kill Candida albicans by Causing Cellular Apoptosis. ACS Medicinal Chemistry Letters 2020, 11, 566-574, https://doi.org/10.1021/acsmedchemlett.0c00030.

21. Ahmad, A.; Wani, M.Y.; Patel, M.; Sobral, A.J.F.N.; Duse, A.G.; Aqlan, F.M.; Al-Bogami, A.S. Synergistic antifungal effect of cyclized chalcone derivatives and fluconazole against Candida albicans. MedChemComm 2017, 8, 2195-2207, https://doi.org/10.1039/c7md00440k.

22. Wani, M.Y.; Silva, M.R.; Krishnakumar, B.; Kumar, S.; Al-Bogami, A.S.; Aqlan, F.M.; Sobral, A.J.F.N. Catalytic Synthesis of 5-Substituted Tetrazoles: Unexpected Reactions and Products. Journal of Heterocyclic Chemistry 2019, 56, 1613-1621, https://doi.org/10.1002/jhet.3542.

23. Rout, Y.; Mobin, S.M.; Misra, R. Tetracyanobutadiene (TCBD) functionalized benzothiadiazole derivatives: effect of donor strength on the [2+2] cycloaddition-retroelectrocyclization reaction. New Journal of Chemistry 2019, 43, 12299-12307, https://doi.org/10.1039/C9NJ01887E.

24. Mekky, A.E.M.; Saleh, T.S.; Al-Bogami, A.S. Synthesis of novel pyrazoles incorporating a phenothiazine moiety: unambiguous structural characterization of the regioselectivity in the 1,3-dipolar cycloaddition 
reaction using 2D HMBC NMR spectroscopy. Tetrahedron 2013, 69, 6787-6798, https://doi.org/10.1016/j.tet.2013.06.028.

25. Daina, A.; Michielin, O.; Zoete, V. SwissTargetPrediction: updated data and new features for efficient prediction of protein targets of small molecules. Nucleic Acids Res 2019, 47, W357-W364, https://doi.org/10.1093/nar/gkz382.

26. Pires, D.E.V.; Blundell, T.L.; Ascher, D.B. pkCSM: Predicting Small-Molecule Pharmacokinetic and Toxicity Properties Using Graph-Based Signatures. Journal of Medicinal Chemistry 2015, 58, 4066-4072, https://doi.org/10.1021/acs.jmedchem.5b00104.

27. Mouilleron, S.; Badet-Denisot, M.-A.; Golinelli-Pimpaneau, B. Ordering of C-terminal Loop and Glutaminase Domains of Glucosamine-6-Phosphate Synthase Promotes Sugar Ring Opening and Formation of the Ammonia Channel. Journal of Molecular Biology 2008, 377, 1174-1185, https://doi.org/10.1016/j.jmb.2008.01.077.

28. Sander, T.; Freyss, J.; von Korff, M.; Reich, J.R.; Rufener, C. OSIRIS, an Entirely in-House Developed Drug Discovery Informatics System. Journal of Chemical Information and Modeling 2009, 49, 232-246, https://doi.org/10.1021/ci800305f.

29. Trott, O.; Olson, A.J. AutoDock Vina: Improving the speed and accuracy of docking with a new scoring function, efficient optimization, and multithreading. Journal of Computational Chemistry 2010, 31, 455461, https://doi.org/10.1002/jcc.21334.

30. Al-Bogami, A.S.; Saleh, T.S.; Mekky, A.E.M.; Shaaban, M.R. Microwave assisted regioselective synthesis and 2D-NMR studies of novel azoles and azoloazines utilizing fluorine-containing building blocks. Journal of Molecular Structure 2016, 1121, 167-179, https://doi.org/10.1016/j.molstruc.2016.05.064.

31. Meanwell, N.A. Improving Drug Candidates by Design: A Focus on Physicochemical Properties As a Means of Improving Compound Disposition and Safety. Chemical Research in Toxicology 2011, 24, 1420-1456, https://doi.org/10.1021/tx200211v.

32. Kearns, E.H.; Di, L. Drug-like properties: concepts, structure design and methods. Elsevier, USA, 2008.

33. Gleeson, M.P. Generation of a Set of Simple, Interpretable ADMET Rules of Thumb. Journal of Medicinal Chemistry 2008, 51, 817-834, https://doi.org/10.1021/jm701122q.

34. Arora, A.; Scholar, E.M. Role of tyrosine kinase inhibitors in cancer therapy. J Pharmacol Exp Ther 2005 , 315, 971-979, https://doi.org/10.1124/jpet.105.084145.

35. Potashman, M.H.; Bready, J.; Coxon, A.; DeMelfi, T.M.; DiPietro, L.; Doerr, N.; Elbaum, D.; Estrada, J.; Gallant, P.; Germain, J.; Gu, Y.; Harmange, J.-C.; Kaufman, S.A.; Kendall, R.; Kim, J.L.; Kumar, G.N.; Long, A.M.; Neervannan, S.; Patel, V.F.; Polverino, A.; Rose, P.; van der Plas, S.; Whittington, D.; Zanon, R.; Zhao, H. Design, Synthesis, and Evaluation of Orally Active Benzimidazoles and Benzoxazoles as Vascular Endothelial Growth Factor-2 Receptor Tyrosine Kinase Inhibitors. Journal of Medicinal Chemistry 2007, 50, 4351-4373, https://doi.org/10.1021/jm070034i.

36. Berta, D.; Villa, M.; Vulpetti, A.; Felder, E.R. Pyrazolyl-benzoxazole derivatives as protein kinase inhibitors. Design and validation of a combinatorial library. Tetrahedron 2005, 61, 10801-10810, https://doi.org/10.1016/j.tet.2005.08.070.

37. Desai, S.; Desai, V.; Shingade, S. In-vitro Anti-cancer assay and apoptotic cell pathway of newly synthesized benzoxazole-N-heterocyclic hybrids as potent tyrosine kinase inhibitors. Bioorganic Chemistry 2020, 94, https://doi.org/10.1016/j.bioorg.2019.103382. 